\title{
Individual Physical Activity Behaviour and Group Composition as Determinants of the Effectiveness of a Childhood Obesity Intervention Program
}

\author{
Liesa Marie Lier $^{\mathrm{a}}$ Christoph Breuer ${ }^{\mathrm{a}} \quad$ Nina Ferrari $^{\mathrm{b}}$ David Friesen ${ }^{\mathrm{c}}$ \\ Fernanda Maisonave ${ }^{c}$ Nikola Schmidt ${ }^{c}$ Christine Graf ${ }^{c}$ \\ ${ }^{a}$ Department of Sports Economics and Sport Management, German Sport University Cologne, Cologne, Germany; \\ ${ }^{b}$ Cologne Center for Prevention and Youth/Heart Center Cologne, University Hospital Cologne, Cologne, Germany; \\ 'Institute of Movement and Neurosciences, German Sport University Cologne, Cologne, Germany
}

\section{Keywords}

Juvenile obesity intervention - Intervention effectiveness .

Physical activity · Group composition

\begin{abstract}
Introduction: Up to now, there is limited clarity on factors that determine the effectiveness of childhood obesity interventions. Objective: This study intends to uncover individual- and program-level predictors of BMI-SDS and fitness to achieve significant, sustainable health improvements. Methods: Data of 249 children with obesity or overweight who participated in an outpatient multidisciplinary program were analysed and compared to 54 waitlist controls. Linear regression models were used to examine associations between individual- and group-level variables and BMI-SDS and fitness. Results: Among intervention children, BMI-SDS decreased by 0.19 units and physical fitness increased by $11.5 \%$, versus a BMI-SDS decrease of 0.07 and a $1.8 \%$ decrease in fitness in the control group. Participants who reported being physically active before the program start achieved greater improvements in BMI-SDS ( $\beta=-0.177, p<$ 0.05 ) and physical fitness $(\beta=0.174, p<0.05)$ than inactive peers. BMI-SDS decreased significantly more for members of
\end{abstract}

karger@karger.com www.karger.com/ofa

Karger $\stackrel{\text { ' }}{5}$

GOPEN ACCESS
(C) 2020 The Author(s)

Published by S. Karger AG, Basel

This article is licensed under the Creative Commons AttributionNonCommercial-NoDerivatives 4.0 International License (CC BYNC-ND) (http://www.karger.com/Services/OpenAccessLicense). Usage and distribution for commercial purposes as well as any distribution of modified material requires written permission. gender-heterogeneous groups $(\beta=0.194, p<0.05)$ with a narrow age range $(\beta=0.152, p<0.05)$. Conclusions: The program under review is effective in counteracting juvenile obesity. The results give reason to believe that forming mixedgender groups with a small age range and providing increased support for reportedly inactive children may improve program effectiveness.

(C) 2020 The Author(s)

Published by S. Karger AG, Basel

\section{Introduction}

Despite associations being found consistently between overweight or obesity and negative health consequences [1], the prevalence of these conditions has increased dramatically over the last decades. In 2016 , over $18 \%$ of children and adolescents aged between 5 and 19 years were affected by overweight or obesity worldwide, while this number was at $4 \%$ in 1975 [2]. Children with obesity often experience hypertension, insulin resistance, and hyperlipidaemia $[3,4]$. Furthermore, being affected by overweight in childhood has negative effects on emotional health [5] and socialisation [6]. Unfortunately, paediatric 
obesity tends to lead to weight problems in adulthood [7]. Studies have estimated a persistence rate of $40-70 \%[8,9]$ for associated negative health consequences in terms of non-communicable diseases [1]. Hence, childhood obesity poses a serious and pressing societal problem, which needs to be addressed.

Presently, no gold standard has been identified in regard to designing childhood obesity programs that are effective for weight reduction and an increase in physical fitness $[10,11]$. Multidisciplinary programs that combine physical activity, education on nutrition, and behavioural therapy have been found to be the most promising [12, 13]. However, most of these studies only aim to reduce weight or BMI-SDS and neglect the impact on changes in physical fitness, which is unfortunate as physical activity and the resulting increase in fitness level lead to health improvements [14]. So far, research on factors with an impact on program success clearly shows that age is positively correlated with program success [15] while there is limited clarity with regard to the impact of initial BMI, as previous sources report different results [16-18]. The few studies that included physical fitness as an outcome variable found that base-level fitness is negatively correlated with increases in fitness [19], or they reported no association between the two [20]. On a program level, program duration [21], the involvement of the family [22], and a group intervention [23] (versus an individual treatment) have been found to have a positive impact on program effectiveness. For group treatments, evidence exists that smaller group sizes are beneficial for program success [24] and that gender diversity has a positive impact on team effectiveness in the scope of work-related project groups [25].

To summarise, while there do exist several studies on the impact of individual-level factors, transparency on the effect of team composition variables on program success is limited. This study intends to address the prevalent shortcomings of existing intervention programs and to shed light on the impact of individual and group determinants on program effectiveness [12]. A better understanding of how to build a truly effective childhood obesity intervention is expected to enable the development of more effective programs. This is not only beneficial for participants who will improve their physical health and associated quality of life, but also for societies as a whole, as excess weight is associated with a significant devaluation of human capital [26].

Effectiveness of a Juvenile Obesity

Intervention

\section{Materials and Methods}

\section{Data Sources and Intervention Description}

In 2003, an outpatient multicomponent family-based program - the Children's Health Interventional Trial (CHILT III) started at the German Sport University, Cologne. The CHILT program is a comprehensive 11-month outpatient intervention (the duration is equivalent to a school year) which builds on the 3 pillars of nutrition, physical activity, and medical/psychosocial support. The primary target groups are children and adolescents with obesity aged between 8 and 16 years and, additionally, children with overweight of the same age group who display risk factors such as dyslipidaemia, hypertension or diabetes type 2, or familial risks for these conditions.

Until 2011, each cohort was split into 2 sub-teams, separating children above 12 years of age from younger participants. Since 2012, the whole cohort was counselled together due to the introduction of the all-day school concept that made it impractical to conduct 2 consecutive sessions. In total, 23 groups participated in the program (16 groups in 8 years between 2003 and 2011, and 7 groups in 7 years between 2011 and 2018).

The children came twice a week and were accompanied by their parents during one of those weekly visits. One visit was scheduled for a regular medical consultation that included weighing, followed by a children's group class in nutrition or psychosocial aspects. In nutrition-focused sessions, the children received information about selecting healthy foods and cooked together. Furthermore, both correct behaviours in the context of bullying and the importance of getting regular physical exercise instead of being sedentary were discussed during the psychosocial classes. While the parents received the same lessons and information from previous classes, the children participated in a 60 -min physical activity program that was mostly conducted in a playful manner. Activities were focused on endurance and moderate resistance training and were complemented by games such as soccer or hockey. The second visit involved only an exercise session of $90 \mathrm{~min}$ for the children. In total, participants performed $150 \mathrm{~min}$ of physical activity per week within the scope of the program. Once per month, the parents joined a group exercise session. All children in the intervention group (IG) missed $<10 \%$ of the lessons.

\section{Anthropometric Data Assessment and Exercise Testing}

At the beginning and end of the program, standard calibrated scales and stadiometers were used to measure and weigh every child [27]. For children in Germany, overweight is diagnosed using the age- and gender-specific nomograms for body mass index developed by the "Arbeitsgemeinschaft Adipositas im Kindes- und Jugendalter" (AGA) [28] which follows the definition of Kromeyer-Hauschild [29]. A BMI below the 90th percentile indicates normal weight, values above the 90th and below the 97th percentile reflect overweight, and a BMI value above the 97 th percentile is defined as obesity. We calculated the BMI standard deviation score $(B M I-S D S)$ as $\left(B M I / M[t]^{L[t]}-1\right) /(L[t] \times S[t])$, where $M[t], L[t]$, and $S[t]$ reflect the age and gender-specific parameters of the child [29].

Resting blood pressure was measured 3 times, and the average of the second and third measurements was recorded. Body fat percentage was measured using a body fat calliper and fasting blood samples were assessed to analyse various health parameters, such as cholesterol, glucose, and insulin (data not shown). 
Table 1. Overview of variables

\begin{tabular}{|c|c|c|}
\hline Variable & Type & Definition \\
\hline \multicolumn{3}{|c|}{ Individual-level variables - demographic and health } \\
\hline Age $^{a}$ & Metric & Age at time of program start \\
\hline Gender $^{\mathrm{a}}$ & Dichotomous & Gender; $1=$ boy, 2 = girl \\
\hline German nationality? & Categorical & Nationality; 1 = German, 2 = non-German \\
\hline Group & Dichotomous & Group status; $0=$ control, $1=$ intervention \\
\hline Physically active? & Dichotomous & Whether or not participant is physically active; $0=$ no, $1=$ yes \\
\hline Body fat percentage & Metric & Body fat as share of total body mass, in $\%$ \\
\hline BMI & Metric & Body mass index (measure of weight adjusted for height), in $\mathrm{kg} / \mathrm{m}^{2}$ \\
\hline BMI-SDS $^{\mathrm{a}}$ & Metric & BMI standard deviation score, according to Kromeyer-Hauschild et al. [29] \\
\hline $\begin{array}{l}\text { Relative maximal power } \\
\text { outputa (Physical fitness) }\end{array}$ & Metric & Maximum power output in watts divided by weight in $\mathrm{kg}$ \\
\hline \multicolumn{3}{|l|}{ Program-level variables } \\
\hline Parents weighed? & Binary & $\begin{array}{l}\text { Whether or not parents have been weighted at program start and end; } \\
0=\text { no, } 1=\text { yes }\end{array}$ \\
\hline Sub-team size & Metric & Number of children in respective sub-team \\
\hline Sub-team gender homogeneity & Metric & $\begin{array}{l}\text { Homogeneity from } 0 \text { to } 100 \% \text {, where } 0 \% \text { implies an equal share of males and } \\
\text { females }\end{array}$ \\
\hline Sub-team age range & Metric & Age of oldest member minus age of youngest member of sub-team (in years) \\
\hline
\end{tabular}

To measure physical fitness, the subjects performed an incremental progressive exercise test on a bicycle ergometer (Ergometrics er900, Ergoline, Bitz, Germany) on which they exercised until exhaustion. Two protocols were used to assess $\mathrm{VO}_{2}$ max: the 2009/2010 cohort followed a ramp-up protocol with a starting workload of $25 \mathrm{~W}$ that increased by $20 \mathrm{~W}$ every $2 \mathrm{~min}$. In the years before, an initial load of $20 \mathrm{~W}$ was increased every 2 min by $0.5 \mathrm{~W}$ per height-adapted reference weight. Subjects were vigorously encouraged to push to their limit during the high-intensity phases of the exercise program. Gas exchange was measured breath-bybreath, and the peak $\mathrm{VO}_{2}$ was determined via a Spirograph system (ZAN 600 CPET, Oberthulba, Germany). The results of the test were related to body weight as $\mathrm{W} / \mathrm{kg}$ and peak $\mathrm{VO}_{2}$ in $\mathrm{mL} / \mathrm{kg} \times$ $\mathrm{min}^{-1}$. Lastly, each family completed a comprehensive questionnaire, providing information on demographics, educational background, health status, and lifestyle patterns (e.g., physical activity and nutrition behaviour) of both the child and the parents.

\section{Sample Description}

The minimum data required per participant to be included in the analysis of this study are age, gender, BMI-SDS, and physical fitness before and after program completion. We decided to use BMI-SDS as it is better suited than BMI to diagnose whether the child is affected by overweight and obesity, as the latter measure varies with gender and age [30]. Physical fitness was measured in maximum power in the scope of this study. Excluding the June 2018 cohort, whose post-assessment had not taken place at the time of submission, a final data set of 303 children remained. The sample consisted of 303 children, of whom 249 (82.2\%) received the intervention and $54(17.8 \%)$ were on the waitlist and hence served as a control group (CG). The IG was split almost evenly in terms of male and female participants ( 47.4 vs. $52.6 \%$, respectively) and comprised mostly children of German origin (83.5\%). The majority of participants in the IG were between 10 and 14 years old (72.7\%), while $11.2 \%$ were younger and $16.1 \%$ were older.

Besides individual data, information on the size and composition of the sub-teams was available. Table 1 provides an overview of all available data.

\section{Statistical Analysis}

Descriptive statistics are shown as mean values, standard deviations, and ranges for both the IG and CG. Baseline differences between the groups were assessed with a $t$ test for metric variables and a $\chi^{2}$ test for categorical and dichotomous variables. In order to determine whether the program was effective, the average changes in BMI-SDS and physical fitness were determined for both IG and CG and tested for significance with a $t$ test. We deployed a CI of $95 \%$ to assess statistical significance. Backwards multiple linear regression models were employed on the data of the 249 intervention children to uncover individual- and program-level variables that influenced the program's success. All statistical analyses were carried out with the program IBM SPSS Statistics version 25.0.

\section{Results}

Table 2 summarises the baseline values (mean, SD, and range) of individual-level demographic and health variables and compares the IG and CG. At $\mathrm{t} 1$, the average BMI-SDS score of the IG was 2.46 (SD 0.45). The average 
Table 2. Baseline demographic and health data and differences between IG and CG

\begin{tabular}{|c|c|c|c|c|c|c|c|c|c|c|c|c|c|}
\hline Measure & \multicolumn{5}{|l|}{ IG } & \multicolumn{6}{|c|}{ CG } & \multicolumn{2}{|l|}{ Comparison } \\
\hline Gender & 249 & - & - & - & - & 54 & - & - & - & - & - & - & 0.884 \\
\hline Body fat $\%$ & 238 & 25.0 & 2.5 & 18.6 & 43.1 & 50 & 23.9 & 1.8 & 19.6 & 28.2 & -1.1 & -1.8 to -0.34 & 0.004 \\
\hline BMI t1 & 249 & 29.9 & 4.8 & 20.5 & 56.6 & 54 & 54 & 4.4 & 21.3 & 39.0 & -1.2 & -2.6 to 0.17 & 0.086 \\
\hline Rel. max. power & $n$ & \multicolumn{2}{|c|}{ Yes, $n(\%)$} & \multicolumn{2}{|c|}{ No, $n(\%)$} & $n$ & \multicolumn{2}{|c|}{ Yes, $n(\%)$} & \multicolumn{3}{|c|}{ No, $n(\%)$} & \multicolumn{2}{|l|}{$p$ value $^{c}$} \\
\hline German nationality? & 230 & \multicolumn{2}{|c|}{$208\left(90^{\mathrm{b}}\right)$} & \multicolumn{2}{|c|}{$22\left(10^{\mathrm{b}}\right)$} & 41 & \multicolumn{2}{|c|}{$39\left(95^{b}\right)$} & \multicolumn{3}{|c|}{$2\left(5^{\mathrm{b}}\right)$} & \multicolumn{2}{|l|}{0.330} \\
\hline Physically active? & 210 & \multicolumn{2}{|c|}{$128\left(61^{b}\right)$} & \multicolumn{2}{|c|}{$82\left(39^{b}\right)$} & 40 & \multicolumn{2}{|c|}{$27\left(68^{b}\right)$} & \multicolumn{3}{|c|}{$13\left(33^{b}\right)$} & \multicolumn{2}{|l|}{0.434} \\
\hline
\end{tabular}

IG, intervention group; CG, control group.

a Significance value as a result of two-tailed $t$ test for metric variables.

${ }^{\mathrm{b}}$ As a share of those children for whom data was available.

c Significance value as a result of the $\chi^{2}$ test for categorical or dichotomous variables.

Table 3. Changes in outcome variables after 11 months $(t 2)$ and differences between IG and CG

\begin{tabular}{|c|c|c|c|c|c|c|c|c|c|c|}
\hline Measure & \multicolumn{4}{|c|}{$\mathrm{IG}(n=249)$} & \multicolumn{4}{|c|}{$\mathrm{CG}(n=54)$} & \multicolumn{2}{|c|}{ Comparison } \\
\hline $\begin{array}{l}\Delta \mathrm{t} 1 \mathrm{t} 2 \mathrm{rel} . \max . \\
\text { power } \% \text { (abs.) }\end{array}$ & $\begin{array}{l}+11.5 \\
(+0.17)\end{array}$ & $\begin{array}{l}22.9 \\
(0.34)\end{array}$ & $\begin{array}{l}-49.8 \\
(-1.01)\end{array}$ & $\begin{array}{l}+154.7 \\
(+1.66)\end{array}$ & $\begin{array}{l}-1.8 \\
(-0.07)\end{array}$ & $\begin{array}{l}19.7 \\
(0.36)\end{array}$ & $\begin{array}{l}-43.1 \\
(-1.04)\end{array}$ & $\begin{array}{l}+63.3 \\
(+0.92)\end{array}$ & $\begin{array}{l}-13.4 \\
(-0.24)\end{array}$ & $\begin{array}{l}<0.001 \\
<0.001)\end{array}$ \\
\hline
\end{tabular}

IG, intervention group; CG, control group.

a Significance value as result of two-tailed $t$ test for metric variables.

maximal power output in the IG was $1.7 \mathrm{~W} / \mathrm{kg}$ body weight (SD 0.37), which is below reported average values (around 2.5 for girls and 3.0 for boys [31]). Within the CG, the children displayed a BMI-SDS of 2.40 (SD 0.51) and a physical fitness of $1.86 \mathrm{~W} / \mathrm{kg}$ body weight (SD 0.40). Post hoc analyses revealed that children in the IG were slightly older $(p<0.05)$ and displayed a higher body fat percentage $(p<0.05)$ than CG children, whose relative maximal power output values were slightly above those of the IG $(p<0.05)$.

Among the intervention children, program-level variables with regard to team size and composition were assessed. Parental weight was measured for approximately $62.2 \%$ of the sample. The average size of an intervention sub-team was 12.4 members with a range of 6-17 members (SD 3.3). Looking at the gender diversity among the sub-teams that received the intervention, the average share of males was at $47.4 \%$ with a range of $25.0-61.1 \%$ (SD 9.2). The average age within a sub-team was 4.47 years with a range of 2.0-8.0 years (SD 1.5).

Table 3 shows the results of the assessment of the program's general effectiveness and reveals that the program can be considered effective, as both BMI-SDS and maximal power output improved significantly among intervention children versus control children (each $p<0.001$ ). With regard to BMI-SDS, intervention participants decreased their BMI-SDS by 0.19 units after the 11-month program, on average. The CG experienced a decline of only 0.07 BMI-SDS units during the same time. The average improvement in relative maximal power output amounted to approximately $11.5 \%$ (plus 0.17 units in absolute values). Among children in the CG, physical fitness 
Table 4. Linear regression of intervention participation on $\Delta$ BMI-SDS $(n=201)$

\begin{tabular}{lrrrrrr}
\hline Measure & \multicolumn{1}{l}{ SE } & \multicolumn{1}{c}{ Std. $\beta$} & \multicolumn{1}{c}{$t$} & $p>|z|$ & VIF \\
\hline Physically active & -0.100 & 0.040 & -0.177 & -2.505 & 0.013 & 1.108 \\
BMI t1 & 0.008 & 0.004 & 0.138 & 1.983 & 0.049 & 1.081 \\
Sub-team size & 0.012 & 0.007 & 0.136 & 1.672 & 0.096 & 1.480 \\
Sub-team gender homogeneity & 0.003 & 0.001 & 0.194 & 2.484 & 0.014 & 1.359 \\
Sub-team age range & 0.026 & 0.013 & 0.152 & 2.030 & 0.044 & 1.252 \\
$R^{2}$ & & & & 0.118 & & \\
Adjusted $R^{2}$ & & & & 0.095 & & \\
Prob. $>$ F & & & & 0.000 & & \\
\end{tabular}

VIF, variance inflation factor.

Table 5. Linear regression of intervention participation on $\Delta$ rel. maximal power output $(n=201)$

\begin{tabular}{lllrrrr}
\hline Measure & $\beta$ & SE & Std. $\beta$ & $t$ & $p>|z|$ & VIF \\
\hline Age & 1.809 & 0.851 & 0.163 & 2.126 & 0.035 & 1.454 \\
Physically active & 8.200 & 3.175 & 0.174 & 2.583 & 0.011 & 1.107 \\
Rel. max. power output t1 & -32.052 & 4.799 & -0.515 & -6.679 & 0.000 & 1.454 \\
BMI t1 & -1.066 & 0.431 & -0.212 & -2.473 & 0.014 & 1.797 \\
$R^{2}$ & & & & 0.194 & & \\
Adjusted $R^{2}$ & & & & 0.178 & & \\
Prob. $>$ F & & & 0.000 & & \\
\hline
\end{tabular}

VIF, variance inflation factor.

decreased by $1.8 \%$ ( -0.07 units in absolute values) during the same 11-month period.

Tables 4 and 5 summarise the results of the analysis of the impact of individual- and program-level variables on effectiveness, showing that for both BMI-SDS and fitness the baseline value in $\mathrm{t} 1$ significantly predicted the magnitude of change in the respective variable. For BMI-SDS, a higher base BMI was associated with a lower reduction in BMI-SDS $(\beta=0.138, p<0.05)$. For physical fitness, the lower the relative maximal power output was at $t 1$, the greater the increase was through the intervention $(\beta=$ $-0.515, p<0.001)$. Children who reported that they were physically active before $t 1$ saw more positive changes in both outcome variables: prior physical activity was associated with a greater reduction in BMI-SDS $(\beta=-0.177$, $p<0.05)$ and a greater increase in fitness $(\beta=0.174, p<$ $0.05)$. Furthermore, the change in physical fitness was also predicted by the participant's base-level BMI ( $\beta=$ $-0.212, p<0.05)$ and age $(\beta=0.163, p<0.05)$. Concerning program-level variables, the improvement in BMISDS was negatively associated with the degree of gender homogeneity within a sub-team $(\beta=0.194, p<0.05)$. We observed the opposite effect for age: the wider the age range was within a sub-team, the lower the participant's reduction was in BMI-SDS $(\beta=0.152, p<0.05)$. Both variables did not significantly predict the change in physical fitness. Whether the parents' weight had been measured or not and the size of the sub-team had no significant impact on either outcome variable. The collinearity statistics showed that we did not face the problem of multicollinearity in this study (variance inflation factors $<10$ [32]).

\section{Discussion}

\section{Main Findings and Contribution of the Study}

The goal of this study was to assess the effectiveness of the 11-month juvenile obesity intervention and to uncover potential determinants of the program's success. The results show that the CHILT intervention effectively improves relevant health outcomes. After the program, the standardised BMI decreased on average by 7.8 versus a $2.8 \%$ decline in the CG, and relative physical fitness im- 
proved on average by $11.5 \%$ versus a decrease of $1.8 \%$ in the CG. The results indicated that children who were physically active prior to the start of the program achieved better results - both in terms of BMI-SDS reduction (approx. 0.12 units) and physical fitness improvement (approx. 13.4 percentage points). In addition, we uncovered that group heterogeneity in terms of gender was beneficial for improvements in BMI-SDS, while age diversity had a negative effect: sub-teams with a lower age range saw greater reductions in BMI-SDS.

\section{Effectiveness and the Impact of Individual-Level}

Factors on BMI-SDS and Physical Fitness

Our study uncovered that children who indicated that they had been physically active before the start of the program were more successful in improving BMI-SDS and physical fitness. Comparable programs that are only open to children who have proven to be motivated for a lifestyle change achieved higher reductions in BMI-SDS [33], which corresponds to this finding. One could hypothesise that physically active children display higher intrinsic motivation for change and are hence more dedicated to the program than their peers [34]. Another reason for the greater perceived effects might be that the program is only a form of lifestyle optimisation for these children, while non-active peers perceive it as a radical change. Furthermore, a reasonable assumption is that prior activity fosters the children's belief in their own ability to partake in and enjoy sports, which may translate into a higher program engagement. The results may provoke the institutions that finance such programs to discuss a potential pre-screening of applicants' physical activity behaviour due to its strong impact on effectiveness.

\section{Impact of Program-Level Factors on BMI-SDS and Physical Fitness}

Our finding that the group composition has considerable potential to influence program effectiveness is good news, as this is at least partly under the control of the program designer. While there does exist proof that gender diversity is beneficial for team success at the workplace $[25,35]$, so far, researchers could not confirm this finding in the context of health promotion [36]. We showed that aiming for a balanced gender distribution within an obesity IG is plausible, as this heterogeneity has a positive impact on the reduction of BMI-SDS. A potential explanation for this relationship might be that the perceived social support and group cohesion, which are predictors of success in health promotion programs [37, 38], have been found to be higher in gender-diverse teams [39].
Furthermore, one could assume that the combination of women's cooperative and encouraging interaction style and men's competitive orientation, which could explain the superior performance of mixed-work teams [35], also drive success in this context. With regard to age, we empirically proved the existing theoretical hypothesis that a juvenile obesity program is more effective in teams with a small age range because it allows for targeting measures towards the specific needs of different age groups which differ considerably as physical and cognitive development is rapid during childhood [40].

\section{Limitations}

Like all empirical analyses, this study is not free of limitations. The size of the sample is limited, and the CG is smaller than the IG; hence, one should interpret all results with caution.

The fact that the models explain only $9.5 \%$ of the variation in BMI-SDS and $17.8 \%$ of the variation in physical fitness is not surprising, as only a subset of potentially impactful factors was considered. We did not assess the effect of the BMI-SDS reduction and physical fitness increase on relevant health parameters such as blood pressure or cholesterol values, as that would have further reduced the statistical population. Furthermore, several individual- and program-level factors were not included in our study, although it would have been interesting to analyse their impact on program effectiveness, with socioeconomic status being the most important factor. As many of the parents did not respond to the question regarding their highest level of education, the number of valid answers reduced the data set available for analysis significantly. In addition, we could not address the question of which type of program works best with regard to frequency, intensity, and duration, as only one program was in the scope of our analysis. As the CHILT program corresponds well to the multimodal intervention structure that has been proven to be the most effective intervention type [12], we instead focused on exploring predictors of effectiveness within that frame.

In addition, selection bias, information bias, and the risk of confounding are 3 major concerns to consider. As the participants themselves (or rather their parents) decided to participate in the program, they potentially share characteristics that distinguish them from other groups. Because some data is self-reported, the study is not free from information bias. Moreover, we could not attain the desired precision with regard to the prior level of physical activity. Lastly, and despite the inclusion of control variables, we still clearly face the risk of confounding, as there 
may be additional factors that we are not aware of which confound the association between the independent variables under consideration and the program's success.

Nonetheless, this study serves as a valuable contribution to research on the effectiveness of childhood obesity interventions in Germany and accentuates the relevance for future work to explore the topic of program success determinants in detail.

\section{Conclusion}

This study intended to explore the question of how the severe and highly relevant problem of childhood obesity can be tackled effectively. The analyses show that the CHILT program, as an example of a multimodal juvenile obesity intervention, not only effectively reduces BMISDS values, but also increases physical fitness among participants. Further examinations should include an analysis of the question regarding to what extent these improvements translate into health improvements that are sustainable in the long term. In addition, we found that the children's physical activity behaviour before the program, and the age and gender composition of the IG predict intervention effectiveness and can hence be leveraged to optimise existing and future childhood obesity programs.

\section{Acknowledgements}

We would like to thank Karen Gottwald, Susanne Vandeven, Lisa Schmidt, and Benjamin Koch for their support during the program. We also thank all participating parents and children.

\section{Statement of Ethics}

Ethics approval was granted by the Sports University of Cologne for the ethic request with the number 107/2014 ("Children's Health InterventionaL Trial III - ein ambulantes Schulungsprorgamm zur Prävention und Therapie von Übergewicht und Adipositas im Kindes- und Jugendalter"). The Ethics Committee consists of Prof. Dr. O. Bock and Prof. Dr. h.c.. E. Meinberg. It was written and is provided as supplementary material.

\section{Conflict of Interest Statement}

The authors have no conflicts of interest to declare.

\section{Funding Sources}

No funding was received for this work.

\section{Author Contributions}

L.M.L. analysed the data and wrote the manuscript. C.B. and C.G. supervised the process of analysis, provided methodological guidance, and revised the manuscript. D.F., N.F., N.S. (who work as sports scientists in the program), and F.M. conducted the medical tests, gathered the data, and calculated variables such as BMISDS. C.G. is the leader of the CHILT III program and developed the study design. All authors reviewed and approved the final version of the manuscript.

\section{References}

1 Field AE, Coakley EH, Must A, Spadano JL, Laird N, Dietz WH, et al. Impact of overweight on the risk of developing common chronic diseases during a 10-year period. Arch Intern Med. 2001 Jul;161(13):1581-6.

2 World Health Organization. Obesity and overweight [Internet]. 2018. Available from: https://www.who.int/news-room/factsheets/detail/obesity-and-overweight.

3 Reilly JJ, Methven E, McDowell ZC, Hacking B, Alexander D, Stewart L, et al. Health consequences of obesity. Arch Dis Child. 2003 Sep;88(9):748-52.
4 Weiss R, Dziura J, Burgert TS, Tamborlane WV, Taksali SE, Yeckel CW, et al. Obesity and the metabolic syndrome in children and adolescents. N Engl J Med. 2004 Jun;350(23): 2362-74.

5 Braet C, Mervielde I, Vandereycken W. Psychological aspects of childhood obesity: a controlled study in a clinical and nonclinical sample. J Pediatr Psychol. 1997 Feb;22(1):59-71.

6 Must A, Strauss RS. Risks and consequences of childhood and adolescent obesity. Int J Obes Relat Metab Disord. 1999 Mar;23(Suppl 2):S2-11.

7 Guo SS, Chumlea WC. Tracking of body mass index in children in relation to overweight in adulthood. Am J Clin Nutr. 1999 Jul;70(1): 145S-8S.
8 Herman KM, Craig CL, Gauvin L, Katzmarzyk PT. Tracking of obesity and physical activity from childhood to adulthood: the Physical Activity Longitudinal Study. Int J Pediatr Obes. 2009;4(4):281-8.

9 Deshmukh-Taskar P, Nicklas TA, Morales M, Yang SJ, Zakeri I, Berenson GS. Tracking of overweight status from childhood to young adulthood: the Bogalusa Heart Study. Eur J Clin Nutr. 2006 Jan;60(1):48-57.

10 Al-Khudairy L, Loveman E, Colquitt JL, Mead E, Johnson RE, Fraser H, et al. Diet, physical activity and behavioural interventions for the treatment of overweight or obese adolescents aged 12 to 17 years. Cochrane Database Syst Rev. 2017 Jun;6(6):CD012691. 
11 Mead E, Brown T, Rees K, Azevedo LB, Whittaker V, Jones D, et al. Diet, physical activity and behavioural interventions for the treatment of overweight or obese children from the age of 6 to 11 years. Cochrane Database Syst Rev. 2017 Jun;6(6):CD012651.

12 Ho M, Garnett SP, Baur L, Burrows T, Stewart L, Neve M, et al. Effectiveness of lifestyle interventions in child obesity: systematic review with meta-analysis. Pediatrics. 2012 Dec; 130(6):e1647-71.

13 Oude Luttikhuis H, Baur L, Jansen H, Shrewsbury VA, O'Malley C, Stolk RP, et al. Interventions for treating obesity in children. Cochrane Database Syst Rev. 2009 Jan;(1):CD001872.

14 Lee IM, Shiroma EJ, Lobelo F, Puska P, Blair SN, Katzmarzyk PT; Lancet Physical Activity Series Working Group. Effect of physical inactivity on major non-communicable diseases worldwide: an analysis of burden of disease and life expectancy. Lancet. 2012 Jul; 380(9838):219-29.

15 Braet C. Patient characteristics as predictors of weight loss after an obesity treatment for children. Obesity. 2006 Jan;14(1):148-55.

16 Epstein LH, Wing RR, Koeske R, Valoski A. A comparison of lifestyle exercise, aerobic exercise, and calisthenics on weight loss in obese children. Behav Ther. 1985;16(4):345-56.

17 Reinehr T, Brylak K, Alexy U, Kersting M, Andler W. Predictors to success in outpatient training in obese children and adolescents. Int J Obes Relat Metab Disord. 2003 Sep;27(9): 1087-92.

18 Brindal E, Freyne J, Saunders I, Berkovsky S, Smith G, Noakes M. Features predicting weight loss in overweight or obese participants in a web-based intervention: randomized trial. J Med Internet Res. 2012 Dec; 14(6):e173.

19 Sisson SB, Katzmarzyk PT, Earnest CP, Bouchard C, Blair SN, Church TS. Volume of exercise and fitness nonresponse in sedentary, postmenopausal women. Med Sci Sports Exerc. 2009 Mar;41(3):539-45.

20 Skinner JS, Jaskólski A, Jaskólska A, Krasnoff J, Gagnon J, Leon AS, et al.; HERITAGE Family
Study. Age, sex, race, initial fitness, and response to training: the HERITAGE Family Study. J Appl Physiol. 2001 May;90(5):1770-6.

21 Gonzalez-Suarez C, Worley A, GrimmerSomers K, Dones V. School-based interventions on childhood obesity: a meta-analysis. Am J Prev Med. 2009 Nov;37(5):418-27.

22 Salmon J, Booth ML, Phongsavan P, Murphy $\mathrm{N}$, Timperio A. Promoting physical activity participation among children and adolescents. Epidemiol Rev. 2007;29(1):144-59.

23 Hoddinott P, Allan K, Avenell A, Britten J. Group interventions to improve health outcomes: a framework for their design and delivery. BMC Public Health. 2010 Dec;10(1): 800.

24 Fagg J, Chadwick P, Cole TJ, Cummins S, Goldstein H, Lewis H, et al. From trial to population: a study of a family-based community intervention for childhood overweight implemented at scale. Int J Obes. 2014 Oct;38(10): 1343-9.

25 Bear JB, Woolley AW. The role of gender in team collaboration and performance. Interdiscip Sci Rev. 2011;36(2):146-53.

26 Cawley J. The economics of childhood obesity. Health Aff. 2010 Mar-Apr;29(3):364-71.

27 Arnold C, Wenta D, Müller-Ehmsen J, Sreeram N, Graf C. Progenitor cell number is correlated to physical performance in obese children and young adolescents. Cardiol Young. 2010 Aug;20(4):381-6.

28 Wabitsch M, Moß A. Konsensbasierte (S2) Leitlinie zur Diagnostik, Therapie und Prävention von Übergewicht und Adipositas im Kindes- und Jugendalter Federführend für die AGA. 2013. Available from: http://www. adipositas-gesellschaft.de/fileadmin/PDF/ Leitlinien/AGA_S2_Leitlinie.pdf.

29 Kromeyer-Hauschild K, Wabitsch M, Kunze D, Geller F, Geiss HC, Hesse V, et al. Percentiles of body mass index in children and adolescents evaluated from different regional German studies. Monatsschr Kinderheilkd. 2001;149(8):807-18

30 Cole TJ, Bellizzi MC, Flegal KM, Dietz WH. Establishing a standard definition for child overweight and obesity worldwide: interna- tional survey. BMJ. 2000 May;320(7244): $1240-3$.

31 Dwyer T, Magnussen CG, Schmidt MD, Ukoumunne OC, Ponsonby AL, Raitakari OT, et al. Decline in physical fitness from childhood to adulthood associated with increased obesity and insulin resistance in adults. Diabetes Care. 2009 Apr;32(4):683-7.

32 Neter J, Wasserman W, Kutner MH. Applied linear regression models. 1989.

33 Reinehr T, Kleber M, Lass N, Toschke AM. Body mass index patterns over $5 \mathrm{y}$ in obese children motivated to participate in a 1-y lifestyle intervention: age as a predictor of longterm success. Am J Clin Nutr. 2010 May; 91(5):1165-71.

34 Linde JA, Rothman AJ, Baldwin AS, Jeffery RW. The impact of self-efficacy on behavior change and weight change among overweight participants in a weight loss trial. Health Psychol. 2006 May;25(3):282-91.

35 Fenwick GD, Neal DJ. Effect of gender composition on group performance. Gend Work Organ. 2001;8(2):205-25.

36 Leahey TM, Kumar R, Weinberg BM, Wing $R R$. Teammates and social influence affect weight loss outcomes in a team-based weight loss competition. Obesity. 2012 Jul;20(7): $1413-8$.

37 Glasgow RE, McCaul KD, Fisher KJ. Participation in worksite health promotion: a critique of the literature and recommendations for future practice. Health Educ Q. 1993; 20(3):391-408.

38 Scherrer P, Sheridan L, Sibson R, Ryan MM, Henley N, Schultz PP, et al. Employee engagement with a corporate physical activity program: the global corporate challenge. Int J Bus Stud. 2010;18(1):125-39.

39 Lee C, Farh JL. Joint effects of group efficacy and gender diversity on group cohesion and performance. Appl Psychol. 2004;53(1):13654.

40 Seburg EM, Olson-Bullis BA, Bredeson DM, Hayes MG, Sherwood NE. A review of primary care-based childhood obesity prevention and treatment interventions. Curr Obes Rep. 2015 Jun;4(2):157-73.
Effectiveness of a Juvenile Obesity Intervention
Obes Facts 2021;14:100-107

DOI: $10.1159 / 000512293$ 